\title{
Silagem de palma forrageira com Gliricidia Sepium: alternativa alimentar para o
}

\section{Semiárido}

\author{
Cactus pear silage with Gliricidia Sepium: food alternative for the semiarid region \\ Ensilaje de palma forrajera con Gliricidia Sepium: alternativa alimenticia para la región semiárida
}

Recebido: 29/01/2021 | Revisado: 05/02/2021 | Aceito: 08/02/2021 | Publicado: 15/02/2021

Moema Kelly Nogueira de Sá
ORCID: https://orcid.org/0000-0001-5748-709X
Universidade Federal do Agreste de Pernambuco, Brasil
E-mail: moema.sa @ gmail.com
Albericio Pereira de Andrade
ORCID: https://orcid.org/0000-0002-1223-394X
Universidade Federal do Agreste de Pernambuco, Brasil
E-mail: albericio3@gmail.com
André Luiz Rodrigues Magalhães
ORCID: https://orcid.org/0000-0003-2211-6795
Universidade Federal do Agreste de Pernambuco, Brasil
E-mail: andre30036@gmail.com
Roberta de Lima Valença
ORCID: https://orcid.org/0000-0003-1341-1602
E-mail: robertalimav@ @otmail.com
Fleming Sena Campos
Universidade Federal do Agreste de Pernambuco, Brasil
ORCID: https://orcid.org/0000-0001-9027-3210
E-mail: flemingcte@yahoo.com.br
Fernando dos Santos Araújo
Universidade Federal do Agreste de Pernambuco, Brasil
ORCID: https://orcid.org/0000-0002-0605-1613
E-mail: ngandosantos005@hotmail.com
Gherman Garcia Leal de Araújjo
ORCID: https://orcid.org/0000-0001-9605-1096
Universidade Federal do Agreste dernambuco, Brasil
E-mail: gherman.araujo@embrapa.br

\begin{abstract}
Resumo
A alimentação de ruminantes em regiões Áridas e Semiáridas sempre foi um desafio para os produtores, devido às condições edafoclimáticas destas regiões. A palma forrageira configura-se como um recurso alimentar estratégico utilizado na alimentação animal nas regiões supracitadas, esta forrageira possui características morfofisiológicas que lhe confere adaptação, além de elevada aceitabilidade pelos ruminantes, a palma é considerada uma importante fonte de energia e água para os animais em períodos de escassez hídrica e alimentar. Contudo, sua utilização de forma exclusiva ou em grandes quantidades pode ocasionar distúrbios metabólicos, de modo que esse recurso alimentar deve estar associado a outros alimentos ricos em fibras e proteína, como por exemplo, o feno de gliricídia, surgindo assim a silagem de dois alimentos de caráter complementar adaptados ao ambiente semiáridos, que supre os animais de proteína, energia e fibra em épocas de escassez. Apesar dos aspectos supracitados essa nova tecnologia ainda é pouco conhecida, tanto na forma de executa-la como em relação aos parâmetros que envolvem o consumo de tal silagem pelos animais. Sendo assim esta revisão tem como objetivo trazer informações sobre o uso de silagem de palma em associação ao feno de gliricídia na alimentação de ruminantes.
\end{abstract}

Palavras-chave: Ensilagem; Conservação de forragem; Gliricidia Sepium; Opuntia Ficus Indica Mill.; Semiárido.

\begin{abstract}
Feeding ruminants in arid and semi-arid regions has always been a challenge for producers, due to the edaphoclimatic conditions in these regions. The cactus pear is configured as a strategic food resource used in animal feeding in the aforementioned regions, this forage has morphophysiological characteristics that give it adaptation, in addition to high acceptability by ruminants, the cactus pear is considered an important source of energy and water for animals in times of water and food scarcity. However, its use exclusively or in large quantities can cause metabolic disorders, so this food resource must be associated with other foods rich in fiber and protein, such as gliricidia hay, thus resulting in the silage of two foods of complementary character adapted to the semiarid environment, which supplies animals with
\end{abstract}


protein, energy and fiber in times of scarcity. Although the mentioned aspects, this new technology is still little known, both in the way of executing it and in relation to the parameters that involve the consumption of such silage by animals. Therefore, this review aims to provide information on the use of palm silage in association with gliricidia hay in the feeding of ruminants.

Keywords: Silage; Forage conservation; Gliricidia sepium; Opuntia ficus indica Mill.; Semiarid.

\section{Resumen}

La alimentación de rumiantes en regiones Áridas y Semiáridas siempre fue un desafío para los productores, debido a las condiciones edafoclimáticas de estas regiones. La palma forrajera se configura como un recurso alimenticio estratégico utilizado en la alimentación animal en las regiones antes mencionadas, este forraje tiene características morfofisiológicas que le otorgan adaptación, además de alta aceptabilidad por parte de rumiantes, la palma es considerada una importante fuente de energía y agua para los animales en períodos de escasez de agua y alimentos. Sin embargo, su uso exclusivo o en grandes cantidades puede provocar trastornos metabólicos, por lo que este recurso alimenticio debe estar asociado a otros alimentos ricos en fibra y proteínas, como el heno de gliricidia, resultando así el ensilaje de dos alimentos de carácter complementario adaptado al medio semiárido, que aporta proteínas, energía y fibra a los animales en tiempos de escasez. A pesar de los aspectos antes mencionados, esta nueva tecnología es aún poco conocida, tanto en la forma de ejecutarla como en relación a los parámetros que implican el consumo de dicho ensilaje por parte de los animales. Por lo tanto, esta revisión tiene como objetivo proporcionar información sobre el uso de ensilaje de palma en asociación con heno de gliricidia en la alimentación de rumiantes.

Palabras clave: Ensilaje; Conservación de forrajes; Gliricidia Sepium; Opuntia Ficus Indica Mill.; Semiárido.

\section{Introdução}

A busca por alternativas alimentares eficientes de baixo custo e que atendam às necessidades dos animais no Semiárido do Brasil tem sido um dos grandes entraves da produção animal, visto que nessa região a precipitação é dispersa e ocorre em poucos meses do ano. $\mathrm{O}$ uso de forragens conservadas surge como estratégia para assegurar a alimentação e a estabilidade nos diferentes sistemas de produção de ruminantes nos momentos de déficit forrageiro (Fluck et al., 2018). A conservação de forragens, sob a técnica de ensilagem, vem sendo difundida nesta região através das instituições de pesquisas e seus parceiros, principalmente pela intensificação dos processos produtivos na pecuária de animais ruminantes (Macêdo et al., 2017). A técnica da ensilagem possibilita o uso de variadas plantas, e que, o excedente forrageiro produzido durante o período das chuvas seja armazenando e utilizado posteriormente. Contudo, deve-se atentar-se quanto a escolha da espécie forrageira para ensilagem, sendo recomendada a utilização de variedades adaptadas às condições edafoclimáticas da região e que apresentem níveis elevados de produtividade por unidade de área, aliado ao um valor nutricional adequado (Perazzo et al., 2019).

Em função da adaptação da palma forrageira às condições edafoclimáticas do Semiárido, esta vem sendo utilizada em sistemas de produção, principalmente nos períodos secos do ano, como um dos principais alimentos volumosos por apresentar alto rendimento de biomassa com produtividades médias de 379,83, 392,83 e 480,17 t matéria verde/ha a cada 02 anos para as cultivares Gigante, Redonda e Miúda respectivamente (Cavalcante et al., 2014), baixo custo, alta aceitabilidade e eficiência no uso da água (Santos et al., 2011; Macedo, Santos, Oliveira \& Perazzo, 2017), além de ser um alimento que supre grande parte das necessidades de água dos animais na época de escassez. Em relação a digestibilidade da matéria seca (MS), a palma apresenta valor superior às silagens de sorgo e de milho (Lopes et al., 2012), todavia, de acordo com Brito et al. (2020), a silagem da palma forrageira possui baixos teores de matéria seca (10 a 13\%) e de proteína bruta $(4,2$ a 6,2\%), o que impede que seja recomendado como alimento exclusivo para ruminantes (Leite et al. 2018), devendo ser associada a uma fonte de fibra e proteína.

Considerando as diversas possiblidades de associações forrageiras para serem utilizadas na produção de silagens mistas, a gliricídia (Gliricidia Sepium) surge como alternativa por se tratar de uma leguminosa adaptada às condições semiáridas e apresentar múltiplos usos nos sistemas agro silviculturais, como fonte proteica na suplementação de dietas, a baixo custo, para ruminantes, (Queiroz et al., 1999), apresenta características desejáveis e que se complementa com a palma forrageira, principalmente quando se observam as características nutricionais de ambas. A gliricídia apresenta de 22 a $30 \%$ de MS e de 20 a 30\% de proteína bruta (Costa, Santos, Oliveira \& Pereira, 2009; Gama et al., 2009; Santana et al. 2019; Valadares Filho et al., 
2018).

No entanto, as pesquisas sobre a associação da palma forrageira com gliricídia ainda são limitadas. Desse modo, esta pesquisa tem como finalidade compreender os aspectos relacionados à composição químico-bromatológica e à qualidade fermentativa da silagem de palma forrageira (Opuntia ficus indica Mill.) associada à gliricídia (Gliricídia sepium (Jacq.) Walp), bem como avaliar o consumo destas por ovinos.

\section{Metodologia}

A presente pesquisa foi desenvolvida por meio de uma revisão bibliográfica de natureza qualitativa. Em pesquisas qualitativas destaca-se a importância da interpretação e das opiniões relatadas pelo pesquisador sobre o objeto de estudo (Pereira et al., 2018). Sendo realizada por meio de uma busca nas principais bases de dados científicos (Scopus, Google Scholar, Scielo e Web of Sciences), além de livros e artigos de diferentes páginas da web destacados no tema central.

O critério de inclusão foi inicialmente artigos em português e inglês publicados nos últimos 20 anos, que abordavam o seguinte tema: a utilização da palma forrageira e gliricídia na alimentação de ruminantes, bem como a silagem destes alimentos combinados.

\section{Revisão da Literatura}

\subsection{Palma Forrageira: cultivo e uso em regiões semiáridas}

A palma forrageira tem sido considerada como um recurso forrageiro importante cultivado e utilizado na base alimentar dos rebanhos, especialmente em regiões Áridas e Semiáridas, chegando a compor até 80\% das dietas (Marques, Gomes, Mourthé, Braz \& Pires Neto, 2017; Oliveira et al., 2018a). De origem mexicana, a palma pertence à família Cactaceae, sendo as espécies do gênero Opuntia e Nopalea as mais utilizadas na alimentação dos ruminantes devido apresentarem elevado potencial de produção de matéria seca por unidade de área e excelente nível de energia (Marques et al., 2017).

A capacidade adaptativa da palma forrageira às condições edafoclimáticas nessas regiões, se deve principalmente aos seus aspectos fisiológicos, tais como: metabolismo fotossintético CAM (Crassulacean Acid Metabolism, o mesmo que Metabolismo Ácido das Crassuláceas), tolerância e resistência à seca e eficiência no uso da água, no entanto, assim como as demais plantas CAM, a palma-forrageira mesmo requerendo menos água que outras plantas, necessita de solos bem adubados e manejo correto para obter alta produção por área e boa qualidade (Silva et al., 2015a).

Em condições de sequeiro, Dubeux Júnior et al. (2015) observaram que a palma forrageira teve produtividade de até 30 toneladas por hectare ao ano (t. ha ${ }^{-1}$ ano $^{-1}$ ), enquanto o milho produziu $1,8 \mathrm{tha}^{-1}$ ano $^{-1}$ nas mesmas condições. Na região semiárida de Pernambuco, verificou-se produtividades anuais da palma forrageira de, aproximadamente, $55 \mathrm{t} \mathrm{ha}^{-1} \mathrm{ano}^{-1}$ de matéria seca (Santos et al., 2011). Sales, Leite, Alves, Ramos e Nascimento (2013), no entanto, obtiveram nas mesmas condições na Paraíba, uma produtividade de $35 \mathrm{t} \mathrm{ha}^{-1}$.ano-1 colhidos com 710 dias após o plantio.

Silva et al. (2015b), analisando três clones de palma forrageira, verificou que a variedade Orelha de Elefante Mexicana (Opuntia stricta Haw. (Haw)) apresenta maior tolerância ao estresse hídrico, quando comparada às espécies do gênero Nopalea spp. Vale ressaltar, que as alterações sazonais e interanuais das condições do ambiente podem provocar alterações no seu crescimento e desenvolvimento (Silva et al., 2015a).

Nesse sentido, em cultivo irrigado da palma, mesmo que utilizando uma quantidade mínima de água, torna-se expressivo, chegando a patamares de 250 a 350t/ha-1/ano-1, com densidades de 50 mil plantas por hectare (Lima et al., 2015). Donato et al. (2014) observou que, utilizando 5 litros de água por metro linear a cada quinze dias, a palma respondeu positivamente em termos de produtividade. 
Além das características adaptativas e de tolerância a restrição hídrica, a palma forrageira se destaca em seus atributos nutricionais, por ser um alimento rico em: energia, carboidratos não-fibrosos (CNF) e matéria mineral, como ferro, zinco, potássio e, principalmente, o cálcio (Lima et al., 2010; Costa et al., 2012; Dessimoni, Batista, Barbosa \& Pinto, 2014), sendo, por sua vez, uma forragem de grande representatividade durante o período de seca, devido a sua suculência, por possuir estrutura vegetativa rica em água (Grobler, Dearlove \& Scholtz, 2010).

Os valores médios da composição químico-bromatológica da palma forrageira são reportados por vários autores podem ser observadas na Tabela 1.

Tabela 1 - Composição química da palma forrageira com base no percentual de matéria seca.

\begin{tabular}{lcccccccc}
\hline Autores & MS & MO & MM & PB & EE & FDN & CT & CNF \\
\hline Wanderley et al. (2012) & 9,39 & 87,43 & 12,57 & 4,92 & 2,17 & $31,87^{*}$ & 84,13 & 50,05 \\
Cavalcante et al. (2014) & 6,37 & 84,07 & 15,94 & 5,42 & 2,98 & $22,05^{*}$ & - & - \\
Nogueira et al. (2016) & 12,92 & - & - & 5,82 & - & 31,60 & - & 47,1 \\
Pessoa et al. (2020) & 9,31 & 89,77 & 10,23 & 5,14 & 1,50 & 33,14 & 82,75 & 49,61 \\
Pereira et al. (2021) & 14,40 & 92,26 & 9,44 & 4,28 & 0,80 & 22,10 & 85,48 & 63,38 \\
\hline Média & 10,26 & 87,87 & 12,47 & 5,01 & 1,84 & - & 82,98 & 53,03
\end{tabular}

MS - Matéria seca; MO - matéria orgânica; MM - matéria mineral; PB - proteína bruta; EE - extrato etéreo; FDN - fibra em detergente neutro; CT - carboidratos totais; CNF - carboidratos não fibrosos; *FDNcp - fibra em detergente neutro, corrigida para cinzas e proteína.

Apesar de apresentar características nutricionais interessantes para a alimentação dos rebanhos, a palma forrageira possui baixos teores de MS, PB e FDN, (Ramos et al., 2013; Aguiar et. al., 2015; Peixoto et al., 2018). Os baixos níveis de FDN são verificados para diferentes gêneros de palma forrageira e, por isso, devem ser considerados, uma vez que os ruminantes necessitam em sua dieta de uma quantidade mínima de FDN de 25\% e de 19\% de FDN efetiva (Alves et al., 2016). Neste sentido, Rodrigues, Pitacas, Reis e Blasco (2016) recomendam a associação com fontes de proteína e volumosos secos, já que a baixa quantidade de fibra que é encontrada na cactácea não é favorável para o funcionamento ruminal adequado. Segundo Almeida (2012), é necessário que a palma forrageira seja fornecida em conjunto com um volumoso fibroso, além de suplementação proteica, conseguindo assim, evitar distúrbios digestivos.

Apesar da baixa quantidade de fibra e proteína a palma contém altos teores de pectina e de carboidratos totais (738 a $852 \mathrm{~g} \mathrm{~kg}^{-1}$ de MS), principalmente os não fibrosos (423 a $650 \mathrm{~g} \mathrm{~kg}^{-1}$ ), o que lhe classifica como um alimento rico em energia, tornando-a apta para ser utilizada em conjunto com outras plantas forrageiras, desde que as demais plantas forneçam os nutrientes limitantes na cactácea, para que tal mistura atue como reserva estratégica de alimentos (Frota et al., 2015, Grünwaldt et al., 2015).

Nesse sentido, vale ressaltar que além de poder ser fornecida in natura ou farelada (Almeida, 2012), outra estratégia pertinente é a de utilizá-la na forma de silagem, sendo esta tecnologia considerada de alto potencial para alimentação animal, especialmente em regiões com escassez hídrica e alimentar (Macêdo et al., 2017; Nobre et al. 2018; Brito et al. (2020).

\subsection{Silagem de palma forrageira associada à leguminosas}

O processo de ensilagem da palma forrageira é uma importante estratégia para reserva de alimento e água em regiões semiáridas, proporcionando inclusive o aproveitamento de outras forrageiras disponíveis, melhorando a qualidade fermentativa e de aceitabilidade animal da silagem de palma, apresentando custo de produção reduzido e possibilitando que os produtores 
tenham uma fonte de renda extra. De acordo com Brito et al. (2020), a combinação da silagem de palma forrageira com leguminosas tem, principalmente, o intuito de melhorar sua composição nutricional e aspectos fermentativos, por meio da complementação da palma forrageira (elevadas concentrações de carboidratos solúveis) com as leguminosas (altos teores proteicos e de matéria seca).

Em geral, dietas contendo palma forrageira apresentam alta aceitabilidade pelos ruminantes, o que possibilita sua oferta em grandes quantidades (Oliveira et al., 2018). Entretanto, o consumo de MS das dietas pode sofrer influência de fatores relativos ao animal (demandas de exigência) ou as características da dieta (digestibilidade, teor de FDN, NDT, composição química e física da forrageira, relação entre volumoso e concentrado, taxa de passagem).

Ao analisar a composição nutricional da silagem mista de palma forrageira com feno de leguminosa, Gusha, Ngongonib e Halimanib (2013), observaram resultados satisfatórios em relação às características das silagens fornecidas, como variação do pH de 4,0 a 4,23 (devido a concentração de açúcares solúveis da palma forrageira) e consequente aumento da concentração de íons de hidrogênio (inibindo as bactérias deletérias). Os autores verificaram, ainda, oscilação dos teores de MS de 37 a $43 \%$, sendo indicativo que a palma pode ser ofertada na silagem aos ruminantes, promovendo um consumo satisfatório sem efeitos laxativos. Gusha, Halimani, Ngongoni e Ncube (2015), ao avaliarem o desempenho de ovinos alimentados com silagem de palma (70\%) e leguminosas (30\%), como ração completa encontraram consumo de MS variando de 0,722 a 0,805 kg de MS/animal/dia.

Matias et al. (2020), utilizando silagem à base de palma forrageira associada a níveis de maniçoba $(0,25 ; 50 ; 75$ e $100 \%)$ na alimentação de caprinos da raça Canindé observaram aumento linear nos teores de ácido butírico, matéria seca, extrato etéreo, proteína bruta, fibra em detergente neutro, fibra em detergente ácido, lignina, celulose, hemicelulose, ingestão de água via bebedouro e água metabólica, e redução do pH, ácido láctico, ácido acético, matéria mineral, carboidratos totais, carboidratos não fibrosos, ingestão de água através dos alimentos, ingestão total de água. Concluindo que a inclusão da maniçoba na silagem de palma forrageira melhorou as características fermentativas e a qualidade nutricional da silagem.

\subsection{Gliricidia sepium (Jacq.) Steud)}

A Gliricidia sepium (Jacq.) Steud., pertence a família Fabaceae, conhecida como gliricídia, é uma leguminosa arbórea e resistente a seca, que vem sendo considerada uma forrageira de interesse comercial e econômico no Semiárido nordestino, devido suas características de uso múltiplo (Edvan et al., 2016; Oliveira et al. 2018b).

Segundo Matos et al. (2005), trata-se de uma forrageira pouco exigente no tocante a fertilidade do solo, possuindo melhor desenvolvimento em regiões com clima quente, onde os meses mais frios apresentam temperatura mínima de $14^{\circ} \mathrm{C}$ a 20 ${ }^{\circ} \mathrm{C}$ e nos meses mais quentes de $34{ }^{\circ} \mathrm{C}$ a $41{ }^{\circ} \mathrm{C}$. A leguminosa tem capacidade de rebrota, suportando cortes periódicos (até três cortes ao ano) e produzindo volumoso de qualidade em condições de baixa disponibilidade hídrica (Marin, Menezes \& Salcedo, 2007; Paulino, Barroso, Lamônica, Costa \& Carneiro, 2011; Edvan et al., 2016).

Ao avaliarem a composição das folhas da gliricídia Costa et al. (2009), constataram os seguintes teores médios: 23,1\% de MS, 24,1\% de PB, 38,8\% de FDN e 24,3\% de FDA. Em regra, o teor de PB destaca-se por se apresentar acima dos 7\%, que o mínimo é necessário para garantir o equilíbrio dos microrganismos ruminais, promovendo o correto funcionamento do rúmen (Sampaio et al. 2009). Além do elevado teor proteico, a referida leguminosa apresenta altos valores de fibra (45\% de FDN) e de cálcio (1,7\%) (Gama et al., 2009).

Apesar do valor nutricional interessante a gliricídia possui reduzida aceitabilidade pelos animais quando utilizada na forma in natura, devido ao odor característico das folhas verdes em função da liberação de compostos voláteis (Costa et al., 2009). Desse modo, para evitar problemas com relutância em relação ao consumo, o fornecimento da gliricídia requer alternativas como: tempo para adaptação dos animais ou conservação, como a fenação ou a ensilagem, assim, a leguminosa passa a ser bem 
consumida pelos ruminantes (Santana Neto, Oliveira \& Valença, 2015). Na Tabela 2, é apresentada a composição químicobromatológica da Gliricídia sepium in natura, em forma de feno e silagem de acordo com autores diversos.

Tabela 2 - Composição química-bromatológica da Gliricidia sepium in natura, feno e silagem.

\begin{tabular}{lccccccc}
\hline Autores & MS & MM & PB & EE & FDN & FDA & CNF \\
\hline Gliricídia in natura & & & & & & & \\
$\quad$ Valadares Filho et al. (2018) & 21,91 & 7,46 & 17,05 & 5,39 & 50,71 & 37,45 & 24,95 \\
$\quad$ Santana et al., (2019) & 23,70 & 6,20 & 19,60 & 3,30 & 56,40 & 46,20 & 17,50 \\
$\quad$ Brito et al. (2020) & 24,75 & 8,20 & 17,92 & 0,89 & 46,59 & 33,39 & 26,04 \\
$\quad$ Silva et al. (2020) & 15,14 & - & 21,96 & 6,24 & 33,01 & 18,99 & - \\
\hline Média & 21,38 & 7,29 & 19,13 & 3,96 & 46,68 & 34,01 & 22,83 \\
\hline Feno de Gliricídia & & & & & & & \\
$\quad$ Pacheco et al. (2014) & 82,53 & 9,36 & 13,9 & 12,33 & 38,56 & 25,42 & 64,41 \\
$\quad$ Bayão et al. (2016) & 91,24 & - & 18,64 & 5,55 & $49,86 *$ & - & 19,47 \\
Carvalho et al. (2017) & 87,36 & 6,16 & 19,20 & 4,27 & 63,94 & 42,02 & - \\
$\quad$ Lemos et al. (2020) & 85,10 & - & 16,40 & - & 49,10 & 27,60 & - \\
\hline Média & 86,55 & 7,76 & 17,04 & 7,38 & 50,37 & 31,68 & 41,94 \\
\hline Silagem de Gliricídia & & & & & & & \\
$\quad$ Campos et al. (2017) & 26,3 & 9,8 & 15,7 & 2,9 & 54,6 & 40,0 & - \\
Carvalho et al. (2017) & 55,2 & 8,4 & 14,0 & 2,5 & 28,0 & 21,9 & 47,1 \\
Oliveira et al. (2018b) & 46,4 & 8,81 & 16,1 & 3,53 & 49,7 & 25,5 & 22,0 \\
$\quad$ Valadares Filho et al. (2021) & 27,10 & 9,80 & 15,23 & 2,90 & 57,45 & 43,91 & - \\
$\quad$ Lemos et al. (2020) & 24,7 & 6,9 & 19,2 & 2,48 & 60,9 & 43,4 & - \\
\hline Média & 35,94 & 8,74 & 16,05 & 2,86 & 50,13 & 34,94 & 34,55 \\
\hline
\end{tabular}

MS - Matéria seca; MO - matéria orgânica; PB - proteína bruta; EE - extrato etéreo; FDN - fibra em detergente neutro; FDA - fibra em detergente ácido; $\mathrm{CNF}$ - carboidratos não fibrosos; *FDNcp - fibra em detergente neutro, corrigida para cinzas e proteína.

Em relação à fenação da gliricídia, assim como os outros fenos de leguminosas são, consideravelmente, superiores aos de gramíneas em relação ao teor proteico (Evangelista \& Lima, 2013), podendo reduzir a suplementação de alimento concentrado proteico (Bayão et al., 2016). Cirne et al. (2013), estudaram as características produtivas de cordeiros em confinamento, observaram que a suplementação com o feno da gliricídia não influenciou o consumo, o peso corporal inicial e final, porém apresentaram melhor eficiência alimentar.

Estudando a substituição parcial do farelo de soja pela silagem e feno de gliricídia, Lemos et al. (2020), observaram maior consumo de matéria seca nos animais alimentados com o feno da gliricídia (1,13 kg de MS/dia) em relação ao farelo de soja e a silagem ( 0,75 e $0,77 \mathrm{~kg}$ de MS/dia, respectivamente). Os autores observaram também maiores ganhos de peso diário e peso da carcaça fria nos animais alimentados com silagem $(0,180 \mathrm{~kg} /$ dia e $14,6 \mathrm{~kg}$ respectivamente $)$ e feno de gliricídia $(0,170$ $\mathrm{kg} /$ dia e 13,8 kg) de gliricídia em relação aos alimentados exclusivamente com farelo de soja $(0,09 \mathrm{~kg} / \mathrm{dia}$ e 11,6 kg) como fonte de proteína. Diante dos resultados supracitados neste trabalho, os autores afirmam que tanto o feno quanto a silagem de gliricídia podem ser utilizados de forma parcial na alimentação de cordeiros em confinamento, porém a silagem demonstra maior potencial. 
Carvalho et al. (2019), estudando a silagem de gliricídia na alimentação de cordeiros observaram coeficientes de digestibilidade aparente da matéria seca e proteína bruta de 0,79 e 0,77 respectivamente, e ganho de peso diário de 203,9 g/dia. Oliveira et al. (2018b) trabalhando com silagem de gliricídia com 0, 200, 400 e $600 \mathrm{~g} / \mathrm{kg}$ de MS de mandioca como volumoso na alimentação de ovinos, observaram comportamento quadrático ( $\mathrm{P}<0,05)$ para o ganho de peso diário, sendo estes de 200, 170, 160 e $210 \mathrm{~g}$, respectivamente. Os autores recomendam a adição de $600 \mathrm{~g} / \mathrm{kg}$ de folhas de mandioca com o objetivo de melhorar o padrão de fermentação e composição química da silagem de gliricídia.

\subsection{Silagem de palma forrageira associada à gliricídia}

As silagens mistas surgem como uma nova alternativa para alimentação de ruminantes consistindo em uma combinação de ingredientes com diferente composição química, como por exemplo, um alimento rico em carboidrato e outro em proteína e fibra, sendo os dois complementares no sentido nutricional e fermentativo. De acordo com Santos et al. (2020), o oferecimento deste tipo de alimento a animais ruminantes minimiza a seleção de ingredientes, melhorando o desempenho dos rebanhos e reduzindo custos em relação às rações convencionais.

Diante da composição químico-bromatológica da gliricídia (Tabela 2), é possível inferir que esta pode ser adicionada a silagens no intuito de reduzir as perdas, melhorando o valor nutritivo e as características fermentativas e sensoriais (Rodrigues et al., 2013). A gliricídia em forma de feno pode atuar como um material absorvente, uma vez que sua adição aumenta o teor de matéria seca da forragem a ser ensilada (Sá, Neiva, Gonçalves \& Cavalcante, 2007; Tavares et al., 2009), e diferentemente do feno de capim, o feno de gliricídia facilita a compactação do material ensilado (Pacheco et al., 2014).

Para que haja uma boa fermentação das forragens, o elevado teor de CNF presente na palma é essencial, pois são utilizados como substrato pelas bactérias presentes no meio, que convertem esses carboidratos em ácidos orgânicos (principalmente em ácido lático) conservando o material ensilado pela acidificação do meio (Macêdo et al., 2017). Como alternativa para melhorar as características nutricionais da silagem de palma, a combinação com o feno de gliricídia é uma possibilidade interessante, pois os altos teores de matéria seca e proteína presentes no feno, aliados às altas concentrações de carboidratos solúveis da palma forrageira configuram-se atributos importantes e desejáveis no processo fermentativo da silagem, resultando em perdas reduzidas, alta estabilidade aeróbia e alto valor nutritivo (Brito et al., 2020). 
Tabela 3 - Composição bromatológica da silagem de palma forrageira e Gliricidia sepium.

\begin{tabular}{|c|c|c|c|}
\hline \multirow{2}{*}{ Composição (\%) } & \multicolumn{3}{|c|}{ Níveis de inclusão de gliricídia (\%) } \\
\hline & 25 & 50 & 75 \\
\hline Matéria Seca & 18,11 & 20,75 & 23,56 \\
\hline Proteína Bruta & 9,41 & 11,23 & 13,51 \\
\hline Matéria Mineral & 10,07 & 9,80 & 9,20 \\
\hline Extrato Etéreo & 1,37 & 1,62 & 2,06 \\
\hline Carboidratos Totais & 79,03 & 76,98 & 73,96 \\
\hline Carboidratos Não Fibrosos & 44,66 & 40,73 & 31,90 \\
\hline Fibra em Detergente Neutro & 36,74 & 39,29 & 45,65 \\
\hline Fibra em Detergente Ácido & 27,03 & 28,58 & 33,67 \\
\hline Hemicelulose & 9,71 & 10,71 & 11,98 \\
\hline
\end{tabular}

Fonte: Adaptado de Brito et al. (2020).

Fatores como o padrão de fermentação e composição química da silagem, exercem influência importante na resposta do animal, quanto à ingestão e digestibilidade do alimento (Santos et al., 2010). Além disso, ao considerar que a silagem de palma forrageira se trata uma forragem úmida (Fontaneli et al., 2009), há a necessidade, mesmo fazendo a sua associação à uma leguminosa, de compreender os mecanismos da ingestão e excreção hídricas.

Santos et al. (2020), estudando o perfil fermentativo e a estabilidade aeróbia de silagens de gliricídia com quatro níveis $(15,30,45$ e $60 \%)$ de inclusão de palma forrageira, observaram que aos 60 dias de ensilagem o pH, N-NH3 e o ácido não diferiram $(\mathrm{P}>0,05)$, porém o teor de ácido lático foi maior $(\mathrm{P}<0,05)$ no tratamento com $60 \%$ de palma, já o propiônico foi maior nos tratamentos com 15 e 30\% de palma (Tabela 4). Os autores concluíram que a palma forrageira (Opuntia spp) em combinação com a gliricídia pode ser adicionada em silagens mista até o nível de $60 \%$, havendo efeitos positivos nos indicadores qualitativos das silagens.

Godoi (2018), trabalhando com silagens de palma forrageira (60\%) e gliricídia (40\%) em comparação com a silagem de milho na alimentação de ovinos sem padrão racial definido, com peso médio inicial de $20 \mathrm{~kg}$, observaram digestibilidade da MS de 723,2 g/kg de MS e 633,9 g/kg de MS, consumo de 1,078 e 0,722 kg/dia de MS e ganho de peso diário de 0,160 e 0,130 $\mathrm{kg} /$ dia, para silagem de palma e gliricídia e silagem de milho, respectivamente. $\mathrm{O}$ autor concluiu que a utilização de silagem compostas de palma forrageira, indicaram maior consumo de matéria seca e nutrientes, menor ingestão de água de bebida, maior eficiência metabólica de proteínas no balanço de nitrogênio e correspondeu de maneira igualitária a silagem de milho nos parâmetros de desempenho de ovinos em confinamento, confirmando o potencial de utilização das silagens a base de palma forrageira, seja exclusivamente ou com outras forrageiras. 
Tabela 4 - Composição bromatológica e fermentativas da silagem de Gliricidia sepium com níveis de inclusão de palma forrageira.

\begin{tabular}{|c|c|c|c|c|}
\hline \multirow{2}{*}{ Itens } & \multicolumn{4}{|c|}{ Nível de inclusão de Palma (\%) } \\
\hline & 15 & 30 & 45 & 60 \\
\hline \multicolumn{5}{|l|}{ Ingredientes da dieta } \\
\hline Palma Forrageira & 15,7 & 30,1 & 43,4 & 55,7 \\
\hline Gliricídia & 64,8 & 51,2 & 38,7 & 27,0 \\
\hline Farelo de Soja & 0,0 & 0,9 & 1,7 & 2,5 \\
\hline Milho & 18,7 & 17,1 & 15,5 & 14,1 \\
\hline Suplemento Mineral & 0,4 & 0,4 & 0,4 & 0,4 \\
\hline Cloreto de amônio & 0,3 & 0,3 & 0,3 & 0,3 \\
\hline \multicolumn{5}{|c|}{ Características químicas e fermentativas da silagem } \\
\hline $\mathrm{pH}$ & 4,00 & 4,00 & 4,02 & 4,00 \\
\hline $\mathrm{N}-\mathrm{NH}_{3}(\% \mathrm{~N}$ total $)$ & 0,05 & 0,05 & 0,05 & 0,06 \\
\hline Ácido Lático & 3,02 & 3,01 & 3,01 & 3,98 \\
\hline Ácido Acético & 0,44 & 0,41 & 0,35 & 0,40 \\
\hline Ácido propiônico & 0,49 & 0,35 & 0,17 & 0,19 \\
\hline
\end{tabular}

Fonte: Adaptado de Santos et al. (2020).

Mediante as informações supracitadas neste texto, fica evidenciada as potencialidades da utilização da silagem de palma forrageira com leguminosas adaptadas ao Semiárido, sobretudo a Gliricidia Sepium. Porém é importante mencionar que é pequeno ainda o número de trabalhos com a utilização dessa silagem na alimentação de ruminantes, sendo a influência do consumo desta no metabolismo animal ainda pouco conhecida, tornando esse ponto limitante na discussão do estudo em questão.

\section{Considerações Finais}

A silagem de palma forrageira associada a leguminosas, sobretudo a gliricídia, é considerada adequada para suprir as exigências nutricionais de ruminantes, inclusive quando é utilizada como ração completa. Tal alimento pode ser considerado uma nova tecnologia de convivência com o Semiárido, podendo também ser utilizados como reserva estratégica de água, auxiliando na dessedentação dos animais.

Torna-se relevante o desenvolvimento de novos estudos que busquem avaliar diferentes níveis de inclusão de leguminosas adaptadas ao semiárido à silagem de palam forrageira, bem como o comportamento de tal alimento frente ao metabolismo animal. Evidencia-se também a necessidade de trabalhos que busquem exibir as potencialidades dessa associação como agente de transformação da realidade produtiva no Semiárido brasileiro. 


\section{Referências}

Aguiar, M. S. M. A., Silva, F. F., Donato, S. L. R., Schio, A. R., Souza, D. D., Meneses, M. A., \& Lédo, A. A. (2015). Síntese de proteína microbiana e concentração de ureia em novilhas leiteiras alimentadas com palma forrageira Opuntia. Semina: Ciências Agrárias, 36(2), 999-1012.

Almeida, R. F. (2012). Palma forrageira na alimentação de ovinos e caprinos no semiárido brasileiro. Revista Verde de Agroecologia e Desenvolvimento Sustentável, 7 (4), 08-14.

Bayão, G. F. V., Edvan, R. L., Carneiro, M. S. S., Freitas, N. E., Pereira, E. S., Pacheco, W. F., Bezerra, L. R., \& Araújo, M. J. (2016). Desidratação e composição química do feno de Leucena (Leucena leucocephala) e Gliricídia (Gliricídia sepium). Revista Brasileira de Saúde e Produção Animal, 17 (3) $365-373$.

Brito, G. S. M. S., Santos, E. M., Araújo, G. G. L., Oliveira, J. S., Zanine, A. M., Perazzo, A. F., Campos, F. S., Lima, A. G. V. O., \& Cavalcanti, H. S. (2020). Mixed silages of cactus pear and gliricídia: chemical composition, fermentation characteristics, microbial population and aerobic stability. Scientific Reports. $10,1-13$.

Campos, F. S., Carvalho, G. G. P., Santos, E. M., Araújo, G. G. L., Gois, G. C., Rebouças, R. A., Leão, A. G., Santos, S. A., Oliveira, J. S., Leite, L. C., Araújo, M. L. G. M. L., Cirne, L. G. A., Silva, R. R., \& Carvalho, B. M. A. (2017). Influence of diets with silage from forage plants adapted to the semi-arid conditions on lamb quality and sensory attributes. Meat science, 124, 61-68.

Carvalho, G. G. P., Rebouças, R. A., Campos, F. S., Santos, E. M., Araújo, G. G. L., Gois, G. C., Oliveira, J. S., Oliveira, R. L., Rufino, L. M. A., Azevedo, J. A. G., \& Cirne, L. G. A. (2017). Intake, digestibility, performance, and feeding behavior of lambs fed diets containing silages of different tropical forage species. Animal Feed Science and Technology, 228, 140-148.

Cavalcante, L. A. D., Santos, G. R. D. A., Silva, L. M. D., Fagundes, J. L., \& Silva, M. A. D. (2014). Respostas de genótipos de palma forrageira a diferentes densidades de cultivo. Pesquisa Agropecuária Tropical, 44(4), 424-433.

Cirne, L. G. A., Baroni, M. R., Oliveira, G. J. C., Jaeger, S. M. P. L., Bagaldo, A. R., Leite, M. C. P., Marques, J. A., \& Carvalho, G. G. P. (2013). Características de carcaça e de não componentes da carcaça de cordeiros suplementados com sal forrageiro de Gliricídia. Arquivo Brasileiro de Medicina Veterinária e Zootecnia, 65 (1), 289-293.

Costa, B. M., Santos, I. C. V., Oliveira, G. J. C., \& Pereira, I. G. (2009). Avaliação de folhas de Gliricídia sepium (JACQ.) Walp por ovinos. Archivos de Zootecnia, 58(33), 41 .

Costa, R. G., Trevino, I. H., Medeiros, G. R., Medeiros, A. N., Pintos, T. F., \& Oliveira, R. L. (2012). Effects of replacing corn with cactus pear (Opuntia ficus indica Mill) on the performance of Santa Inês lambs. Small Ruminant Research, 102(1), 13-17.

Dessimoni, G. V., Batista, A. G., Barbosa, C. D., \& Pinto, N. A. V. D. (2014). Composição bromatológica, mineral e fatores antinutricionais da palma forrageira. Tecnologia \& Ciência Agropecuária, 8 (3), 51-55.

Donato, P. E. R., Pires, A. J. V., Donato, S. L. R., Bonomo, P., Silva, J., Aquino, A. A. (2014). Morfometria e rendimento da palma forrageira 'Gigante' sob diferentes espaçamentos e doses de adubação orgânica. Revista Brasileira de Ciências Agrárias, 9(1), $151-158$.

Dubeux Júnior., J. C. B., Santos, M. V. F., Melo, A. C. L., Cunha, M. V., Ferreira, D. A., Santos, D. C., Lira, M., \& Silva, M. C. (2015). Forage potential of cacti on drylands. Acta Horticullturae (ISHS), Leuven, 1(1067-24), 181-186.

Edvan, R. L., Carneiro, M. S. De, Silva, S. E. B., Albuquerque, D. R., Pereira, E. S., Bezerra, L. R., Silva, A. L., \& Araújo, M. J. (2016). Análise de crescimento da gliricídia submetida a diferentes manejos de corte. Archivos de Zootecnia, 65(250), 166.

Evangelista, A. R., \& Lima, J. A. (2013). Produção de feno. Informe Agropecuário, 34(277), 43-52.

Fluck, A. C., Schafhäuser Júnior, J., Alfaya Júnior, H., Costa, O. A. D., Farias, G. D., Scheibler, R. B., Rizzo, F. A., Manfron, J. A. S., Fioreze, V. I., Rösler, D. C. (2018). Composição química da forragem e do ensilado de azevém anual em função de diferentes tempos de secagem e estádios fenológicos. Arquivo Brasileiro de Medicina Veterinária e Zootecnia, 70(6), p.1979-1987.

Fontaneli, R. S., Santos, H. P, \& Fontaneli, R. S. (2009). Forrageiras para integração lavoura pecuária-floresta na região sul-brasileira. Passo Fundo, Rio Grande do Sul: Embrapa.

Frota, M. N. L. D. et al. Palma forrageira na alimentação animal. Embrapa Meio-Norte, 2015. 47 p.

Gama, T. C. M., Zago, V. C. P., Nicodemo, M. L. F., Laura, V. A., Volpe, E., \& Morais, M. G. (2009). Composição bromatológica, digestibilidade “in vitro” e produção de biomassa de leguminosas forrageiras lenhosas cultivadas em solo arenoso. Revista Brasileira de Saúde Produção Animal, $10,560-572$.

Godoi, P. F. A. (2018). Potencial de silagens a base de palma forrageira em dietas para ovinos no Semiárido nordestino. 87f. Dissertação (Mestrado em Ciência Animal e Pastagens). Universidade Federal Rural de Pernambuco - UFRPE. Garanhuns.

Grobler, S. M., Dearlove, K., \& Scholtz, M. M. (2010). Palatibility of Opuntia varieties available in South Africa for dryland sheep. South African Journal of Animal Science, 40(5), 495-498.

Grunwaldt, J. M., Guevara, J. C., \& Grünwaldt, E. G (2015). Review of scientific and technical bibliography on the use of Opuntia spp. as forage and its animal validation. Journal of the Professional Association for Cactus Development. (17), 13-32.

Gusha, J., Halimani, T. E., Ngongoni, N. T., \& Ncube, S. (2015). Effect of feeding cactus legume silages on nitrogen retention, digestibility and microbial protein synthesis in goats. Animal Feed Science and Technology, (206),1-7.

Gusha, J., Ngongoni, N. T., \& Halimani, T. E. (2013). Nutritional composition and effective degradability of four forage trees grown for protein supplementation. Online Journal of Animal Feed Research, 3(4),170-175. 
Leite, J. R. A., Sales, E. C. J. D., Monção, F. P., Guimarães, A. D. S., Rigueira, J. P. S., \& Gomes, V. M. (2018). Nopalea cactus pear fertilized with nitrogen: morphometric, productive and nutritional characteristics. Acta Scientiarum. Animal Sciences. 40, 1-8.

Lemos, A. J., da Silva Morais, J. A., de Souza, S. F., Oliveira, V. S., Andrade, A. C. S., \& dos Santos, A. C. P. (2020). Consumo, comportamento ingestivo, desempenho, características de carcaça e rendimento de cortes comerciais de cordeiros em terminação alimentados com feno ou silagem de gliricídia. Archives of Veterinary Science, 25(2).

Lima, G. F. C., Silva, J. G. M., Aguiar, E. M., \& Teles, M. M. (2010). Reservas forrageiras estratégicas para a pecuária familiar no semiárido: palma, fenos e silagem. EMPARN, Natal. 53p.

Lima, G. F. C., Wanderley, A. M., Guedes, F. X., Rego, M. M. T., Dantas, F. D. G., Silva, J. G. M., Novaes, L. P., \& Aguiar, E. M. (2015). Palma Forrageira irrigada e adensada: uma reserva Forrageira estratégica para o Semiárido Potiguar. EMPARN. Parnamirim, Rio Grande do Norte. 62p.

Lopes, E. B. (2012). Palma forrageira: cultivo, uso atual e perspectivas de utilização no Semiárido nordestino. EMEPA-PB.

Macedo, A. J. S., Santos, E. M., Oliveira, J. S., \& Perazzo, A. F. (2017). Produção de silagem na forma de ração à base de palma: Revisão de Literatura, Revista Electrónica de Veterinária, 18(9), 1-11.

Marin, A. M. P., Menezes, R. S. C., \& Salcedo, I. H. (2007). Produtividade de milho solteiro ou em aléias de Gliricídia adubado com duas fontes orgânicas. Pesquisa Agropecuária Brasileira, 42(5) 669-677.

Marques, O. F. C., Gomes, L. S. P., Mourthé, M. H. F., Braz, T. G. S., \& Pires Neto, O. S. (2017). Palma forrageira: cultivo e utilização na alimentação de bovinos. Cadernos de Ciência Agrária, 9(1) 75-93.

Matias, A. G. S., Araujo, G. G. L., Campos, F. S., Moraes, S. A., Gois, G. C., Silva, T. S., \& Voltolini, T. V. (2020). Fermentation profile and nutritional quality of silages composed of cactus pear and maniçoba for goat feeding. The Journal of Agricultural Science, 158(4), 304-312.

Matos, L. V., Campello, E. F. C., \& Resende, A. S. de. (2005). Plantio de leguminosas arbóreas para produção de moirões vivos e construção de cercas ecológicas. Seropédica: Embrapa Agrobiologia, 100 p. Embrapa Agrobiologia. Sistemas de Produção, 3.

Nobre, I. S. et al. Ingestive behaviour and thermoregulation in sheep fed forage cactus silage undergoing intermitent water supply. Semin. Cienc. Agrar. 39, 1683-1694 (2018).

Nogueira, M. S., Santos, E. M., Araújo, G. G. L., Pinho, R. M. A., Nunes, C. S. S. M., Parente, H. N. (2016). 'Ensilagem de palma forrageira'. in: Santos, E.M., Parente, H.N., Oliveira, I.S., Parente, M.O.M. (org.), ensilagem de plantas forrageiras para o semiárido, EDUFMA, São Luiz, MA.

Oliveira, J. P. F., Ferreira, M. A., Alves, A. M. S. V., Melo, A. C. C., Andrade, I. B., Urbano, S. A., Suassuna, J. M. A., B arros, L. J. A., Melo, T. T. B. (2018a). Carcass characteristics of lambs fed spineless cactus as a replacement for sugarcane. Asian-Australasian Journal Animal Science, $31,529-536$.

Oliveira, A. P. D., Bagaldo, A. R., Loures, D. R. S., Bezerra, L. R., Moraes, S. A., Yamamoto, S. M., Araújo, F. L., Cirne, R. L., \& Oliveira, R. L. (2018). Effect of ensiling gliricidia with cassava on silage quality, growth performance, digestibility, ingestive behavior and carcass traits in lambs. Animal Feed Science and Technology, 241, 198-209.

Pacheco, W.F., Carneiro, M. S. S., Edvan, R.L., Arruda, P. C. L., Carmo, A. B. R. (2013). Valor nutritivo de silagens de capim elefante (Pennisetum purpureum Shum) com feno de gliricídia (Gliricídia sepium (Jacq.) Walp). Revista Verde de Agroecologia e Desenvolvimento Sustentável, 8 (2) $240-246$.

Pacheco, W. F., Carneiro, M. S. S., Pinto, A. P., Edvan, R.L., Arruda, P. C. L., Carmo, A. B. R. (2014). Perdas fermentativas de silagens de capim-elefante (Pennisetum purpureum Schum) com níveis crescentes de feno de gliricídia (Gliricídia sepium). Acta Veterinária Brasílica, 8(3) $155-162$.

Paulino, G. M., Barroso, D. G., Lamônica, K. R., Costa, G. S., Carneiro, J.G.A. (2011). Desempenho da gliricídia no cultivo em aleias em pomar orgânico de mangueira e gravioleira. Revista Árvore, 35(4), 781-789.

Peixoto, M. J. A., Carneiro, M. Do S. De S., Amorim, D. S., Edvan, R. L., Pereira, E.S., Costa, M.R.G.F. (2018). Características agronômicas e composição química da palma forrageira em função de diferentes sistemas de plantio. Archivos de Zootecnia, 67(257), 35-39.

Perazzo, A. F., Santos, F. N. S., Santos, E. M., Oliveira, J. S., Pinho, R. M. A., Silva, M. A. (2019). Produção de forrageiras no Semiárido brasileiro. Ensilagem no Nordeste do Brasil. São Luiz: EDUFMA, 1, 29-86.

Pereira A. S. et al. (2018). Metodologia da pesquisa científica. UFSM.

Pereira, G. A., Santos, E. M., Oliveira, J. S., Araújo, G. G. L., Paulino, R. S., Perazzo, A. F., Ramos, J. P. F., César Neto, J. M., Cruz, G. F. L., \& Leite, G. M. (2021). Intake, nutrient digestibility, nitrogen balance, and microbial protein synthesis in sheep fed spineless-cactus silage and fresh spineless cactus. Small Ruminant Research, 194, 106293.

Pessoa, D. V., Andrade, A. P., Magalhães, A. L. R., Teodoro, A. L., Santos, D. C., Araújo, G. G. L., Medeiros, A. N., Nascime nto, D. B., Valença, R. L., \& Cardoso, D. B. (2020). Forage cactus of the genus Opuntia in different with the phenological phase: Nutritional value. Journal of Arid Environments, 181, 104243.

Queiroz, M. A. A., Goedert, C. O., Ramos, S. R. R. (1999). Recursos Genéticos e Melhoramento de Plantas para o Nordeste brasileiro. Petrolina-PE: Embrapa Semiárido, Brasília-DF: Embrapa Recursos Genéticos e Biotecnologia.

Rodrigues, A. M., Pitacas, F.I., Reis, C.M.G., Blasco, M. (2016). Nutritional value of Opuntia ficus-indica cladodes from portuguese ecotypes. BuLIGarian. Journal of Agricultural Science, 22(1), 40- 45. 
Sá, C. R. L., Neiva, J. N. M., Gonçalves, J. S., Cavalcante, M. A. B. (2007). Composição bromatológica e características fermentativas de silagens de capimelefante (Pennisetum purpureum, Schum.) com níveis crescentes de adição do subproduto da Manga (Mangifera indica L.). Revista Ciência Agronômica, 38(2), 199-203.

Sales, A. T., Leite, M. L. M. V., Alves, A. Q., Ramos, J. P. F., Nascimento, J. P. (2013). Crescimento vegetativo de palma forrageira em diferentes densidades de plantio no Curimatú Paraibana. Revista Tecnologia e Ciência Agropecuária, João Pessoa, 7, 19-24.

Ramos, A. O., Ferreira, M. D. A., Véras, A. S. C., Costa, S. B. D. M., Conceição, M. G. D., Silva, E. C. D., Salla, L. E., \& Souza, A. R. D. L. (2013). Diferentes fontes de fibra em dietas a base de palma forrageira na alimentação de ovinos. Revista Brasileira de Saúde e Produção Animal, 14(4), 648-659.

Sampaio, C.B., Detmann, E., Lazzarini, I., Souza, M. A., Paulino, M. F., Valadares, S. C. (2009). Rumen dynamics of neutral detergente fiber in cattle fed lowquality tropical forage and supplemented with nitrogenous compounds. Revista Brasileira de Zootecnia, 38(3) 560-569.

Santana, J. C. S., Morais, J. A. S., Santos, M. S. A. A., Gurgel, A. L. C., Muniz, E. N., Oliveira, V. S. (2019). Característ icas fermentativas, composição química e fracionamento da proteína da silagem de gliricídia submetida a diferentes períodos de fermentação. Boletim de Indústria Animal, 76, 1-9.

Santana Neto, J. A., Oliveira, V. S., Valença, R. L. (2015). Leguminosas adaptadas como alternativa alimentar para ovinos no semiárido - revisão. Revista de Ciências Agroveterinárias, Lages, 14(2), 191-200.

Santos, M. V. F., Castro, A. G. G., Perea, J. M., García, A., Guim, A., Hernández, M. P. (2010). Fatores que afetam o valor nutritivo das silagens de forrageiras tropicais. Archivos de Zootecnia. 59 (R), 25-43.

Santos, P. M., Voltolini, T. C., Cavalcante, A. C. R., Pezzopane, J. R. M., Moura, M. S. B., Silva, T. G. F., Bettiol, G.M., Cruz, P.G. (2011). Global climatic changes and animal production: future scenarios for the Brazilian tropical semiarid. Revista Caatinga. 4, 1176-1196.

Santos, F. N. S., Santos, E. M., Oliveira, J. S., Medeiros, G. R., Zanine, A. M., Araújo, G. G. L., Perazzo, A. F., Lemos, M. L. P., Pereira, D. M., Cruz, G. F. L., Paulino, R. S., \& Oliveira, C. J. B. (2020). Fermentation profile, microbial populations, taxonomic diversity and aerobic stability of total mixed ration silages based on Cactus and Gliricidia. The Journal of Agricultural Science, 158(5), 396-405.

Silva, A. E. M., Lira, A. T., Ferreira, M. A., Barros, L. J. A., Melo, T. T. B., Siqueira, T. D. Q., Soares, L. F. P., Costa, C. T. F. (2015b). Bagaço de cana-deaçúcar como volumoso exclusivo em dietas para ovinos. Revista Brasileira de Saúde e Produção Animal. 16, (1), 118-129.

Silva, T. G. F., Primo, J. T. A., Morais, J. E. F. Diniz, W. J. S., Souza, C. A. A., Silva, M. C. (2015a). Crescimento e produtividade de clones de palma forrageira no semiárido e relações com variáveis meteorológicas. Revista Caatinga, 28, 2.

Silva, H. W., Favarin, S., Andriguetti, S. C., Domiciano, D., Godinho, A. M. M., Araújo, E. B., Souza, H. O., \& Xavier, W. A. (2020). Desenvolvimento vegetativo, produção de biomassa e composição químico-bromatológica de gliricídia em condições de clima temperado/Vegetative development, biomass production and chemical-bromatological composition of gliricidia in temperate climate conditions. Brazilian Journal of Development, 6(1), 847-859.

Tavares, V. B., Pinto, J. C., Evangelista, A. R., Figueiredo, H. C. P., Ávila, C. L. S., Lima, R. F. (2009). Efeitos da compactação, da inclusão de aditivo absorvente e do emurchecimento na composição bromatológica de silagens de capim-Tanzânia. Revista Brasileira de Zootecnia, 38, 40-49.

Valadares Filho, S. C., Lopes, S. A., Chizzotti, M. L., Bissaro, L. Z. CQBAL 4.0. Tabelas Brasileiras de Composição de Alimentos para Ruminantes. 2018. Disponível em: www.cqbal.com.br.

Wanderley, W. L., Ferreira, M. de A., Andrade, D. K. B., Véras, A. S. C., Lima, L. E., Dias, A. M. A. (2012). Palma forrageira (Opuntia fícus indica Mill) em substituição à silagem de sorgo (Sorghum bicolor (L.) Moench) na alimentação de vacas leiteiras. Revista Brasileira de Zootecnia, 31(1) $273-281$. 